\title{
AS CONTRIBUIÇÕES DE ANATOLI VASSILIEVITCH LUNATCHARSKI PARA A EDUCAÇÃO BRASILEIRA NA ATUALIDADE
}

\author{
LAS CONTRIBUCIONES DE ANATOLI VASSILIEVITCH LUNATCHARSKI A LA \\ EDUCACIÓN BRASILEÑA ACTUAL
}

\section{THE CONTRIBUTIONS OF ANATOLI VASSILIEVITCH LUNATCHARSKI TO THE BRAZILIAN EDUCATION AT THE PRESENT TIME}

Marta CHAVES ${ }^{1}$

Paula Gonçalves FELICIO ${ }^{2}$ Jani Alves da Silva MOREIRA ${ }^{3}$

RESUMO: Este texto apresenta as contribuições das proposições do intelectual russo Anatoli Vassilievitch Lunatcharski (1875-1933) para a Educação brasileira na atualidade. Nesta elaboração, de cunho bibliográfico, nos fundamentamos nos pressupostos da Ciência da História, que evidencia a relevância de atentarmo-nos à especificidade da temática em questão e estabelecer como necessidade considerar a dinâmica da sociedade capitalista na atualidade, assim como as relações econômicas e políticas, as quais são indissociáveis das questões educacionais. Realizamos um levantamento bibliográfico, sobretudo, da produção acadêmica afeta ao intelectual no período compreendido entre 2007 e 2017, discorremos sobre os princípios da escola soviética e a proposta de Educação defendida por Lunatcharski. Consideramos fundamental a formação de professores, inicial ou contínua, amparada nos clássicos. Por meio dos estudos contínuos é possível planejarmos e reconduzirmos as intervenções pedagógicas, que podem favorecer a aprendizagem e o desenvolvimento intelectual dos estudantes, em favor de uma Educação humanizadora.

PALAVRAS-CHAVE: Lunatcharski. Ciência da história. Formação de professores.

RESUMEN: Este texto presenta las contribuciones de las propuestas del intelectual ruso Anatoli Vassilievitch Lunatcharski (1875-1933) para la Educación brasileña en la actualidad. En esta elaboración, de carácter bibliográfico, nos basamos en los supuestos de la Ciencia de la Historia, que destaca la relevancia de prestar atención a la especificidad del tema en cuestión y establecer como necesidad considerar la dinámica de la sociedad capitalista actual, así como las relaciones económicas y políticas, que son indisociables de las cuestiones educativas. Realizamos una investigación bibliográfica, sobre todo, de la producción académica afecta a los intelectuales en el periodo comprendido entre 2007 a 2017, hablamos de los principios de la escuela soviética y la propuesta de Educación

\footnotetext{
${ }^{1}$ Universidade Estadual de Maringá (UEM), Maringá - PR - Brasil. Professora Associada do Departamento de Teoria e Prática da Educação e Coordenadora do Curso de Pedagogia. Doutorado em Educação (UFPR). ORCID: https://orcid.org/0000-0002-8089-1450.E-mail: mchaves@uem.br

${ }^{2}$ Universidade Estadual de Maringá (UEM), Maringá - PR - Brasil. Doutoranda no Programa de Pós-Graduação em Educação (PPE/UEM). ORCID: https://orcid.org/0000-0002-5946-9802. E-mail: paulag f@outlook.com ${ }^{3}$ Universidade Estadual de Maringá (UEM), Maringá - PR - Brasil. Docente Adjunto do Departamento de Teoria e Prática da Educação e do Programa de Pós-Graduação em Educação (PPE/UEM). Doutorado em Educação (UEM). ORCID: https://orcid.org/0000-0002-3008-0887. E-mail: jasmoreira@uem.br
} 
defendida por Lunatcharski. Consideramos fundamental la formación de docentes, inicial o continua, apoyada en los clásicos, a través de los estudios continuos es posible planear y redireccionar las intervenciones pedagógicas, que pueden favorecer el aprendizaje y el desarrollo intelectual de los estudiantes, a favor de una Educación humanizadora.

PALABRAS CLAVE: Lunatcharski. La ciência de la história. Formación de docentes.

ABSTRACT: This paper presents the contributions of the propositions of the Russian intellectual Anatoli Vassilievitch Lunatcharski (1875-1933) for Brazilian Education at the presente. In this elaboration, of bibliographic nature, we based ourselves on the presumptions of the Science of History, which highlights the relevance of paying attention to the specificity of the theme in question and establishing as a necessity the consideration of the dynamics of the capitalist society today, as well as the economic and political relations, which are inseparable from educational matters. We carried out a bibliographic review, mostly, of the academic production that affects the intellectual in the period between 2007 and 2017, we discussed the principles of the Soviet school and the proposal of Education defended by Lunatcharski. We consider essential the education of teachers, initial or continuous, supported by the classics, through continuous studies it is possible to plan and reconduct pedagogical interventions, which can favor students' learning and intellectual development, in favor of a humanizing education.

KEYWORDS: Lunatcharski. Science of history. Teachers' education.

\section{Reflexões iniciais}

Este texto objetiva estudar as contribuições das proposições do intelectual russo Anatoli Vassilievitch Lunatcharski (1875-1933) para a Educação brasileira na atualidade. Nesta elaboração, de cunho bibliográfico, nos fundamentamos nos pressupostos da Ciência da História e da Teoria Histórico-Cultural, em que vigora a premissa de que os homens e suas ideias são resultado de sua existência material. Os pressupostos desse referencial defendem que a Educação não é um fenômeno explicável por si mesmo, o que significa asseverar que os fenômenos são explicados pela organização econômica e política da sociedade e que não são compreendidos isoladamente: a humanidade e suas ideias são resultados de sua existência material, isto é, "não é a consciência que determina a vida, mas a vida que determina a consciência" (MARX; ENGELS, 1993).

Atentarmo-nos à especificidade da temática em questão não exclui, ao contrário, estabelece como necessidade considerar a dinâmica da sociedade capitalista na atualidade. Como denunciam os estudos de Antunes (2009; 2017), o desenvolvimento do modo de produção capitalista não é sinônimo do desenvolvimento para as condições objetivas de vida; não se efetiva, portanto, o sentido humano ou a plenitude da vida, pois em igual proporção 
diariamente temos a expressão da miséria. De fato, são os "tempos sombrios" propalados por Arendt (2008); à miséria para as condições básicas de sobrevivência, soma-se a miséria para o desenvolvimento da condição intelectual.

$\mathrm{Na}$ atualidade presenciamos no Brasil um acentuado debate afeto à Educação, se configuram discursos, proposições e documentos oficiais ou orientadores que reafirmam a relevância da Educação escolar e sua relação com as questões econômicas e políticas. Em nosso entendimento, tais discussões expressam um princípio e um conteúdo político que necessitam ser compreendidos.

Nas últimas décadas do século XX, a partir da Constituição Federal de 1988, seguiram-se estudos, debates e legislações. Mencionamos a Lei de Diretrizes e Bases da Educação (LDB) (Lei nº 9.394/96) e a Base Nacional Comum Curricular (BNCC) (BRASIL, 2017), a qual anuncia orientações a fim de nortear os currículos dos sistemas e redes de ensino do Brasil, assim como as propostas pedagógicas das escolas públicas e privadas de Educação Infantil, Ensino Fundamental e Ensino Médio, amparada no desenvolvimento de competências, em busca de atender às demandas do mercado de trabalho, fato que se relaciona com a ideologia e concepção da sociedade vigente.

A partir das assertivas, consideramos o cenário econômico e político no qual as instituições e os educadores estão inseridos, assim como analisamos tal conjuntura, em que no início do século XXI, acentua-se a condição de miséria. Em oposição à lógica do capital, a relevância de estudos contínuos, uma formação de professoras rigorosa e consistente, amparada nos clássicos, pode favorecer a reflexão e recondução da prática educativa, o que implica levar à discussão a função da escola e do conhecimento.

Lunatcharski (1988), em seu artigo intitulado "Premissas sociológicas da Pedagogia Soviética", afirmava que os escritos marxistas, sobretudo as premissas sociológicas, são significativos para a análise da sociedade e instrumento indispensável para mudá-la. Dessa forma, a finalidade da educação relaciona-se com o regime vigente, "[...] dos processos sociais gerais, e a sociedade marxista pode demonstrar que existe uma concordância total entre a instrução pública e o fim social para o qual ela se desenvolve e que ela serve" (LUNATCHARSKI, 1988, p. 189), isto é, a Educação relaciona-se indissociavelmente com as

\footnotetext{
${ }^{4}$ Artigo publicado pela primeira vez na Enciclopédia Pedagógica, em 1927. A primeira Enciclopédia Pedagógica Soviética, redigida por ocasião do décimo aniversário da Revolução Russa de Outubro de 1917, foi organizada em três volumes, a fim de analisar e sistematizar, em uma perspectiva marxista, questões da educação e do ensino, na qual se encontravam referências e estudos afetos à pedagogia, aos setores do ensino público e do trabalho educativo e cultural. Lunatcharski, Krupskaia, Blonski, Chatski e outros intelectuais compuseram a redação do material (DNEPROV, 1988).
} 
questões econômicas e políticas. Nessa acepção, refletimos a seguir sobre as contribuições do intelectual para a Educação brasileira na atualidade.

\section{Lunatcharski e os princípios da escola soviética: contribuições para a Educação brasileira na atualidade}

Anatoli Vassilievitch Lunatcharski foi um intelectual que participou significativamente da luta pela construção de uma consciência revolucionária, após a Revolução Russa de outubro de 1917, pela edificação de uma nova sociedade e pela formação do novo homem comunista. Conforme afirma o historiador italiano Manacorda (2006, p. 313), a referida Revolução “[...] levou pela primeira vez ao poder, num vasto império, a classe operária e seu partido político, rompendo a unidade burguesa do mundo moderno: um fato que, seja qual for o julgamento sobre ele e o êxito atual, marca uma virada na história".

A Revolução Soviética significou historicamente a busca por consolidar uma sociedade comunista, um novo regime econômico e político, amparado no princípio de produzir e distribuir as riquezas elaboradoras socialmente a todos. A Educação era umas das fundamentais tarefas consideradas pelos dirigentes bolcheviques, o que significava constituir uma ampla Educação da classe trabalhadora e superar o analfabetismo (LOMBARDI, 2017).

Em síntese, "a história do Breve Século XX não pode ser entendida sem a Revolução Russa e seus efeitos diretos e indiretos [...]" (HOBSBAWN, 2011, p. 89). Em concordância com Chaves (2018, p. 6), “[...] nem as baixas temperaturas, nem a fome quase absoluta impediram os soldados, trabalhadores e militantes revolucionários, de tornar a República Socialista Soviética uma potência na indústria, na ciência e na cultura".

Nesse sentido, a Educação foi priorizada desde os primeiros momentos do regime soviético. Havia a necessidade de criar uma nova sociedade, e para tanto era fundamental uma proposta educacional em favor da formação do novo homem comunista. Em 26 de outubro de 1917 foram criados os Comissários do Povo, dentre eles o Comissariado do Povo para a Instrução Pública (Narkompros). Anatoli Lunatcharski foi nomeado por Lênin presidente e responsável, juntamente com a atuação fundamental de Nadezhda Konstantinovna Krupskaia $^{5}$, pelo sistema educacional da Rússia.

Em meio aos desafios e difíceis condições dos primeiros anos do poder soviético, com o país ainda em condições de guerra civil e fome, Lunatcharski $(1965 ; 1974 ; 1975 ; 1988$;

\footnotetext{
${ }^{5}$ Nadezhda Konstantinovna Krupskaia (1869-1939) nasceu em São Peterburgo, em 26 de fevereiro de 1869. Combatente, a esposa de Lênin dedicou sua juventude e vida à Revolução Russa e elaborou proposições educacionais tendo por base a defesa do conhecimento para o desenvolvimento humano (CHAVES, 2018; FELICIO, 2018).
} 
2018) propagou as bases do novo sistema de Educação, elaborou os princípios para a edificação da escola comunista, criou uma ampla rede de Educação pré-escolar, de instrução profissional secundária e de ensino superior, assim como instituições de ensino e de cultura. Fundamentado no método marxista, discutiu a Educação escolar, a Educação extraescolar, o ensino politécnico, a instrução como base da cultura e a arte (FELICIO, 2018).

Cabe ressaltar que, ao realizarmos o levantamento de fontes e de estudos elaborados sobre a temática em questão, verificamos a ausência de artigos, livros, dissertações e teses que tenham como tema principal o autor Lunatcharski e suas elaborações afetas à Educação, sobretudo, estudos sobre sua contribuição para a Educação brasileira atual.

Mencionamos o artigo sobre o intelectual em questão, de autoria de Zoia Prestes e Elizabeth Tunes, intitulado "Anatoli Vassilievitch Lunatcharski e os princípios da escola soviética", publicado em 2017 na Movimento Revista de Educação. E o livro "Lunacharski y la organización soviética de la educación y de las artes (1917-1921)”, escrito por Sheila Fitzpatrick, publicado pela Siglo XXI de España Editores, em 1977, tradução de Antonio J. Desmonts - cujo título original é "The Commissariat of Enlightenment-Soviet organization of Education and the Arts under Lunacharsky october 1917-1921”, publicado em 1970 pela autora em questão.

Na obra de Sheila Fitzpatrick intitulada "Lunacharski y la organizacion soviética de la educacion y de las artes (1917-1921)", a autora ampara seus estudos em documentos do período (1917-1921), na Rússia, a fim de apresentar, brevemente, os aspectos biográficos de Lunatcharski e a sua atuação como Comissário do Povo para Instrução Pública, por vezes criticada por setores do Partido Comunista, mas apoiada por Krupskaia, que fortaleceu a ideia de que a função da revolução era fazer da cultura e das escolas uma instituição de desenvolvimento e formação de um novo homem comunista, e não apenas uma instituição de controle e preparação profissional. A autora também permite elucidar alguns dos bastidores das decisões afetas à educação que mobilizaram diversas orientações presentes nos primeiros anos da revolução bolchevique (FREITAS, 2017). Em geral, as pesquisas desenvolvidas por Fitzpatrick têm como temática a história social e cultural do período soviético, particularmente nas práticas cotidianas dos camponeses e dos trabalhadores industriais (FITZPATRICK, 1977; 2017).

Em relação aos livros, localizamos em algumas obras relativas à história da Educação soviética menção a Lunatcharski. Por exemplo, na obra "Makarenko: o nascimento da pedagogia socialista" (CAPRILES, 1989), em que o autor se refere a Lunatcharski como o "responsável por toda a transformação legislativa da escola russa e o criador dos sistemas de 
ensino primário, superior e profissional da futura pedagogia socialista" (CAPRILES, 1989, p. 29-30). Identificamos ainda obras que, além de mencionarem a nomeação de Lunatcharski como Comissário do Povo, discutem sua atuação política e a organização proposta para a Educação soviética (FISCHER, 1967; ORSO; MALANCHEN; CASTANHA, 2017; PRESTES, 2012).

No tocante aos aspetos biográficos de Lunatcharski, sua formação intelectual e literária e sua atuação como Comissário do Povo, citamos os escritos dos livros de Mariátegui (2012) e Trotski (2007). Também na obra de Lênin (1968) encontramos artigos e discursos do autor que versam sobre orientações políticas ao Comissariado do Povo para Instrução Pública, assim como menção ao seu presidente. E localizamos obras que têm anexos de textos que Lunatcharski redigiu (FREITAS; CALDART, 2017; GOMIDE, 2017; HAUPT; MARIE, 1972; LÊNIN, 1968; REED, 2017).

No que se refere à produção acadêmica, teses e dissertações, no período de 2007 a 2017, buscamos na Coordenação de Aperfeiçoamento de Pessoal de Nível Superior (Capes) e na Biblioteca Digital Brasileira de Teses e Dissertações (BDTD), pelos termos "Lunatcharski e Educação Soviética"; selecionamos então 10 dissertações e 04 teses, as quais, em geral, apenas citam o autor ao tratar a Educação soviética e politécnica. Isto é, apesar da menção a Lunatcharski, os trabalhos selecionados não versam sobre os aspectos biográficos do revolucionário, a proposição educacional defendida pelo autor para a organização soviética e suas contribuições para refletirmos a Educação na atualidade.

Da mesma forma, vale mencionar, conforme Chaves (2018), que no tocante aos escritos da História da Educação ou da Pedagogia, a elaboração de Lunatcharski é praticamente anulada. São raras as referências aos estudiosos russos, incluindo Krupskaia e Anton Semionovich Makarenko (1888-1939), por exemplo. Em concordância com Chaves (2018), Lunatcharski, assim como Krupskaia (19--) e Makarenko (1981), responsáveis e idealizadores dos princípios políticos para a Educação, Psicologia e Arte da URSS, amparados nos pressupostos marxistas, são clássicos políticos da Teoria Histórico-Cultural, o que justifica a relevância de serem conhecidos e estudados nos cursos de formação inicial e continuada de professores. Nas palavras de Saviani e Duarte (2010, p. 431), o clássico “define-se, pois, pelas noções de permanência e referência”, isto é, os autores defendem o acesso aos clássicos como condição necessária à formação humana.

Nas elaborações de Lunatcharski, o intelectual proferiu discursos e escreveu artigos afetos à Educação, particularmente, à organização e estruturação da Educação Soviética, após a Revolução bolchevique, nos quais, em geral, discute sobre a Educação escolar, a Educação 
extraescolar, o ensino politécnico, a instrução como base da cultura e a arte. Afirma ainda a relação indissociável entre as questões educacionais com as tarefas econômicas e políticas do período em questão para edificação de uma nova sociedade. Em suas palavras: "não pode permitir-se que as dificuldades do momento pisem as flores das primeiras esperanças do proletariado na possibilidade de um desenvolvimento harmonioso do homem" (LUNATCHARSKI, 1988, p. 4).

Nos anos imediatamente a seguir à Revolução socialista de outubro, os congressos afetos à instrução pública desempenharam uma relevante função na definição do desenvolvimento da nova escola, na formação das bases ideológicas e teóricas da educação soviética, e, sobretudo, no que diz respeito à formação dos professores para compor os fundamentos da escola. Destacamos que apenas no ano de 1918 se realizaram 164 congressos locais de docentes e 81 congressos dos trabalhadores da instrução pública (DNEPROV, 1988).

No I Congresso de toda a Rússia para a Instrução Pública, que decorreu de 25 de agosto a 4 de setembro de 1918, em Moscou, foram discutidas as atividades que contribuíram para elaborar as bases fundamentais da organização socialista da instrução pública. Lunatcharski (1988), ao pronunciar seu discurso no referido Congresso, afirmou que o Estado se confronta com novos desafios e está em intenso trabalho de organização, como, por exemplo, a sua Constituição ${ }^{6}$, considerada provisória. O objetivo firmado foi possibilitar ao povo todas as riquezas, assim, a luta pela escola era uma condição essencial. O Comissário explicava:

Quando fui nomeado Comissário para a Instrução Pública, não podia deixar de me aperceber desta enorme responsabilidade de que o povo me investiu. Trata-se de transmitir o mais rápida e amplamente possível o saber ao povo, de destruir o privilégio do conhecimento de que só uma ínfima parcela da sociedade gozava. Também aqui, salta igualmente aos olhos que não se tratava de nos apoderarmos da escola: a escola é tão caduca e inútil como o aparelho de Estado. Não podíamos racionar como o Governo Provisório, dizendo que íamos prescrever algumas modificações aos inspetores de distrito; tínhamos de desmantelar tudo; era perfeitamente claro que a escola deve ser objeto de uma transformação revolucionária (LUNATCHARSKI, 1988, p. 11, grifo nosso).

\footnotetext{
6 "A primeira Constituição soviética foi a Constituição da RSFSR, adoptada pelo V Congresso dos Sovietes de Toda a Rússia em 1918. A Constituição consagrou o poder soviético como forma da ditatura do proletariado, suprimiu a propriedade privada capitalista e fundiária, proclamou a igualdade de todos os povos da Rússia etc. A Constituição assegurava a todos os trabalhadores da Rússia a participação na gestão do Estado, e privava os exploradores do direito de voto. Em 1924, o II Congresso dos Sovietes da URSS aprovou a primeira Constituição da União das Repúblicas Socialistas Soviéticas” (DNEPROV, 1988, p. 249).
} 
A partir da assertiva, compreendemos que a nova organização educacional, proposta pelo comissário, necessitava romper com a escola de classes e o conhecimento apenas para as classes privilegiadas. Lunatcharski (1988, p. 33), ao criticar a educação burguesa, constata que, por um lado, a escola formará senhores que poderão dominar os outros com segurança e arrogância, "[...] sem se interrogarem se tem o direito de fazer isso e sabendo manter-se nessa posição dominante com todas as presas e garras em riste; e, por outro lado, a escola formará escravos, ou seja, indivíduos dóceis [...]". Isto é, o ensino na sociedade capitalista não impõe os mesmos objetivos para a educação das classes dominantes e para a classe trabalhadora, a qual é considerada objeto e mão de obra.

Nesse sentido, Lunatcharski (1988) postulava que a Educação tinha uma relação indissociável com as tarefas econômicas e políticas, especialmente nos primeiros anos do governo soviético, nos quais se buscava a constituição da sociedade comunista. Para tal, era necessário considerar os seguintes elementos: o poder governamental, econômico e o conhecimento; assim, a luta da classe trabalhadora pela liberdade, isto é, uma tomada de consciência ao máximo, se edificaria.

Ao refletirmos sobre o conceito liberdade, defendido por Lunatcharski, constatamos que na atualidade, há valores e conceitos em constante discussão e em diferentes esferas, como nas instituições escolares, mídias, entre outras. Pensemos na liberdade anunciada na esfera econômica e explicada por Antunes (2009, p. 234):

Entre as distintas formas de flexibilização - em verdade, precarização podemos destacar, por exemplo, a salarial, de horário, funcional ou organizativa. A flexibilização pode ser entendida como "liberdade da empresa" para desempregar trabalhadores; sem penalidades, que a produção e as vendas diminuem; liberdade, sempre para a empresa, para reduzir o horário de trabalho ou de recorrer a mais horas de trabalho; possibilidades de pagar salários reais mais baixos do que a paridade de trabalho exige; possibilidade de subdividir a jornada de trabalho em dia e semana segundo as conveniências das empresas, mudando os horários e as características do trabalho (por turno, por escala, em tempo parcial, horário flexível etc.); dentre tantas outras formas de precarização da força de trabalho.

Antunes (2009) revela, no que se refere às questões econômicas, a falsa ideia de liberdade anunciada pelas empresas como flexibilização que, com efeito, é a precarização do trabalho, e favorece, particularmente, aos empresários. De acordo com o autor, sendo o trabalho uma necessidade humana e desenvolvimento do seu potencial emancipador, devendo-se superar o trabalho que aliena, pensemos, brevemente, nas contradições presentes nesse processo na sociedade capitalista: "O que deveria ser fonte de humanidade se converte 
em desrealização do ser social, alienação e estranhamento dos homens e mulheres que trabalham" (ANTUNES, 2009, p. 232).

Nesse cenário, Moraes (2001) ressalta as decorrentes imposições do sistema capitalista em todas as esferas. Os países em desenvolvimento se obrigam a buscar alternativas que lhes possibilitem a participação no complexo jogo econômico mundializado. Tais ações têm efeito sobre as práticas sociais, e particularmente sobre a educação - e se apresentam, de modo significativo, nos documentos, planos, diretrizes e nas políticas públicas educacionais, seguindo as orientações dos organismos internacionais, as quais, de modo geral, asseguram a centralidade da educação básica nas atuais circunstâncias políticas e econômicas (FELICIO, 2018).

Lunatcharski (1988) afirma que a vida em si e o sistema econômico e político na sua totalidade educam uma nova geração. O intelectual, ao estudar o modo como a instrução pública está organizada na sociedade burguesa, menciona a defesa de Marx sobre as contradições existentes, assim como a ilusória igualdade dos direitos políticos e a desigualdade econômica, de fato. Em relação ao conceito de liberdade, Lunatcharski (1988, p. 228), amparado nos escritos de Engels, afirma que o comunista "durante a luta é a humanidade escravizada que arranca os seus grilhões vivos constituídos por corpos humanos e pela viva consciência dos seus inimigos de classe", isto é, a busca pela liberdade, por meio do conhecimento.

Reiteramos que o conceito de liberdade amplamente discutido na atualidade é anunciado de maneira aparente, fato que testemunhamos na esfera econômica, que fundamenta as políticas educacionais. Conforme Antunes $(2009 ; 2017)$, a ideia de que as reformas educacionais se referem à sua concepção de uma escola flexibilizada para atender as exigências e os imperativos empresariais; uma formação superficial e instituída para considerar as necessidades do mercado de trabalho. O pesquisador afirma que a Educação, em geral, particularmente do século XXI, não poderá, nesta lógica, desenvolver um sentido humanista e crítico, ou seja, uma Educação emancipadora (FELICIO, 2018).

Chaves (2014) pontua que as ações escolares cotidianas estão tomadas de elementos que podem favorecer uma Educação humanizadora, plena ou subserviente, desoladora e desencantadora. Uma Educação de excelência, em harmonia com a defesa de Lunatcharski (1988), contrariando a lógica capitalista dominante, não desconsidera a condição de miséria. Nas instituições educativas, essa desigualdade econômica se expressa de inúmeras formas: na organização do espaço, na escassez de materiais didático-pedagógicos, na desvalorização do conhecimento científico e da arte, assim como na fragilidade e aligeiramento da formação e 
capacitação inicial ou continuada dos professores. Tais elementos expressam o valor que a sociedade capitalista atribui às crianças, sobretudo oriundas da classe trabalhadora (CHAVES, 2011).

Ao considerar os enfretamentos para a superação da lógica capitalista, Lunatcharski (1988, p. 189) destaca que a escola tem uma dupla tarefa: por um lado, possibilitar a todos as conquistas do passado no tocante à ciência e à arte, e, por outro lado, superar a lógica da escola de classes. Sendo assim, fundamentado nos pressupostos marxistas, reafirma a necessidade de compreendermos "[...] a incompatibilidade particularmente profunda que existe entre as formas da instrução pública ditadas pelos interesses e a vontade das classes dirigentes, e a educação que responderia aos interesses das massas exploradas". Assim, a sociologia pedagógica tem por tarefa essencial analisar "raízes naturais" da instrução pública e relacionar os princípios pedagógicos aos objetivos do comunismo, opondo-se às teorias burguesas, isto é, superar o antigo e elaborar o novo, "ser um combatente e um criador".

O intelectual em questão, em seus escritos, refletia: que homem queremos formar? Em sua concepção, o sujeito que satisfaça suas necessidades e desenvolva todas as suas capacidades humanas. Para tal, deve receber uma formação geral, tornar-se um homem para o qual nada do que é humano lhe é alheio, para, assim, realizar suas escolhas, sejam pessoais ou profissionais, em favor do coletivo. A escola "deve dar à criança, ao adolescente, conhecimentos politécnicos, isto é, a assimilação, com a ajuda de exemplos, dos princípios de base, das leis fundamentais, dos processos essenciais do trabalho aperfeiçoado, cientificamente organizados" (LUNATCHARSKI, 1988, p. 232).

Ao discutir sobre o desenvolvimento intelectual, técnico e artístico humano, Lunatcharski (1988) afirma que os homens devem ter suas especificidades e aprimorá-las, contudo, não se limitar apenas a determinada área do conhecimento; faz-se necessário o acesso ao conhecimento, à ciência e à arte. Assim, o comissário defendia a organização de uma Escola Única do Trabalho e considerava o ensino politécnico essencial nesse processo. Dessa forma, a educação é um processo que compreende dois elementos principais: "o do crescimento ininterrupto da organização da experiência humana [...] e o método que permite dar acesso às crianças a cada etapa desse progresso fazendo-as assimilar a experiência adquirida ao longo dos milénios" (LUNATCHARSKI, 1988, p. 138).

Ao refletirmos sobre as contribuições dos escritos de Lunatcharski para a atualidade, compreendemos que a organização de procedimentos didático-pedagógicos, priorizando o conhecimento científico e a arte, pode proporcionar uma aprendizagem e desenvolvimento que favoreçam a emancipação humana (FELICIO, 2018). 
Nessa perspectiva, os escritos de Vigotski (2009, p. 23) são elucidativos: “A conclusão pedagógica que se pode chegar com base nisto consiste na afirmação da necessidade de ampliar a experiência da criança [...] Quanto mais a criança viu, ouviu e vivenciou mais ela sabe e assimilou [...]". O autor explica a relevância dos estudantes terem vivências ricas e enriquecedoras em seu processo educativo. Quanto maior o acesso às elaborações humanas, mais possibilidades terão para aprender e desenvolver, em especial, suas funções psicológicos superiores, como memória, atenção, concentração, linguagem, imaginação e criação, assim como o desenvolvimento afetivo, estético, do espírito coletivo e solidário, em favor de uma educação emancipadora, argumento que se harmoniza com a defesa de Lunatcharski (1988).

Nessa lógica, em conformidade com Faustino (2006), a educação só poderá ser emancipadora e promover a autonomia se associada aos conhecimentos científicos acumulados historicamente pela humanidade à disposição de todos, como quer Lunatcharski (1988). Só assim o indivíduo poderá conseguir compreender a condição de exploração na qual se encontra, fazer escolhas políticas, culturais e verificar que as mudanças podem e devem ocorrer.

\section{Considerações finais}

Lunatcharski seguiu em dedicação à sua atuação como militante, desenvolvendo seus estudos e elaborações fundamentais para compreendermos a relação entre conhecimento, cultura e formação humana. $O$ intelectual participou significativamente da luta pela construção de uma consciência revolucionária russa, especificamente nas revoluções de 1905 e outubro de 1917, para a edificação de uma nova sociedade e a formação do novo homem comunista. Após a Revolução de Outubro de 1917, uma das principais tarefas era possibilitar o acesso ao conhecimento à classe trabalhadora. O intelectual defendia uma Educação cuja função é o pleno desenvolvimento das capacidades e potencialidades humanas (FELICIO, 2018).

A atenção atribuída aos desafios e êxitos alcançados na Rússia, assim como a proposta educacional elaborada por Lunatcharski (1988), contribuem para nossas reflexões para a Educação brasileira da atualidade, sobretudo no que se refere às questões econômicas e políticas, estabelecendo a necessidade de considerar a dinâmica da sociedade capitalista atual e suas implicações no âmbito educacional. Ao considerarmos o poder governamental, econômico e o conhecimento da luta da classe trabalhadora pela liberdade, isto é, uma tomada de consciência ao máximo, se edificaria, como pontua Lunatcharski (1988). 
Portanto, reafirmamos a relevância e necessidade da formação de professores, inicial ou continuada, amparada no estudo dos clássicos, para compreendermos a dinâmica econômica e política para além do imediato, da aparência (KOSIK, 1976). Assim, se firma a possibilidade de superar práticas docentes fragmentadas e esvaziadas de sentido e significado. Consideramos que por meio dos estudos contínuos é possível planejarmos e reconduzirmos as intervenções pedagógicas, priorizando a ciência e a arte, com recursos aprimorados, que mobilizem o desenvolvimento intelectual, assim como o espírito solidário e coletivo dos estudantes, como propôs Lunatcharski.

\section{REFERÊNCIAS}

ANTUNES, R. Da educação utilitária fordista à multifuncionalidade liofilizada. In:

REUNIÃO NACIONAL DA ANPED, 38., 2017, São Luís do Maranhão. Anais [...]. São Luís do Maranhão: UFMA, 2017. p. 1-15. Disponível em: http://38reuniao.anped.

org.br/sites/default/files/resources/programacao/trabalhoencom_38anped_2017_gt11_textoric ardoantunes.pdf. Acesso em: 08 maio 2021.

ANTUNES, R. Século XXI: nova era da precarização estrutural do trabalho? In: ANTUNES, R.; BRAGA, R. (org.). Infoproletários: degradação real do trabalho virtual. São Paulo: Boitempo, 2009. p. 231-238.

ARENDT, H. Homens em tempos sombrios. Trad. Denise Bottmann. São Paulo: Companhia das Letras, 2008.

BRASIL. Ministério da Educação. Base Nacional Comum Curricular. Educação é a Base. Brasília, DF: MEC, 2017. Disponível em: http://basenacionalcomum.mec.gov.br/wp-content/ uploads/2018/04/BNCC_19mar2018_versaofinal.pdf. Acesso em: 08 maio 2021.

CAPRILES, R. Makarenko: o nascimento da pedagogia socialista. São Paulo: Scipione, 1989.

CHAVES, M. A formação e a educação da criança pequena: os estudos de Vigotski sobre a arte e suas contribuições às práticas pedagógicas para as instituições de Educação Infantil. Araraquara, 2011. 72 f. Trabalho de Pós-Doutoramento - Faculdade de Ciências e Letras, Universidade Estadual Paulista, Araraquara, 2011.

CHAVES, M. Formação contínua e práticas educativas: possibilidades humanizadoras. In: CAÇÃO, M. I.; MELLO, S. A.; SILVA, V. P. (org.). Educação e desenvolvimento humano: contribuições da abordagem histórico-cultural para a educação escolar. Jundiaí: Paço Editorial, 2014. p. 119-139.

CHAVES, M. Krupskaya: uma pedagoga revolucionária. 2018. 21 p. Digitado.

DNEPROV, E. D. Comentários. In: LUNATCHARKI, A. V. Artigos e discursos sobre a instrução e a educação. Trad. Filipe Guerra. Moscovo: Edições Progresso, 1988. p. 246-299. 
FAUSTINO, R. C. Política educacional nos anos de 1990: o multiculturalismo e a interculturalidade na educação escolar indígena. 2006. 334 f. Tese (Doutorado em Educação) - Universidade Federal de Santa Catarina, Florianópolis, 2006.

FELICIO, P. G. Anatoli Vassilievitch Lunatcharski: a educação na Rússia Revolucionária (1917-1929). Orientadora: Profa. Dra. Marta Chaves. 2018. 173 f. Dissertação (Mestrado em Educação) - Universidade Estadual de Maringá, Maringá, 2018.

FISCHER, L. A vida de Lênin. Rio de Janeiro: Civilização Brasileira, 1967.

FITZPATRICK, S. A Revolução Russa. Trad. José Geraldo Couto. São Paulo: Todavia, 2017.

FITZPATRICK, S. Lunacharski y la organización soviética de la educación y de las artes (1917-1921). Trad. Antonio J. Desmonts. Madrid, Espanha: Siglo XXI de España Editores, 1977.

FREITAS, L. C. Prefácio. In: KRUPSKAYA, N. K. A construção da pedagogia socialista: escritos selecionados. Trad. Natalya Pavlova e Luiz Carlos de Fretas. São Paulo: Expressão Popular, 2017. p. 7-18.

FREITAS, L. C.; CALDART, R. S. Notas. In: KRUPSKAYA, N. K. A construção da pedagogia socialista: escritos selecionados. Trad. Natalya Pavlova e Luiz Carlos de Freitas. São Paulo: Expressão Popular, 2017. p. 267-273.

GOMIDE, B. B. (org.). Escritos de outubro: os intelectuais e a revolução russa, 1917-1924. São Paulo: Boitempo, 2017.

HAUPT, G.; MARIE, J-J. Los bolcheviques. Trad. Manuel de la Escalera. Cuidad de México: Ediciones Era, 1972.

HOBSBAWM, E. Era dos extremos: o breve século XX: 1914-1991. Trad. Marcos Santarrita. São Paulo: Companhia das Letras, 2011.

KOSIK, K. Dialética do concreto. Trad. Célia Neves e Alderico Toríbio. São Paulo: Paz e Terra, 1976.

KRUPSKAIA, N. K. Acerca de la educación comunista: articulos y discursos. Trad. V. Sanchez Esteban. Moscú: Ediciones em Lenguas Estranjeras (19--).

LÊNIN, V. I. Cultura e revolução cultural. Trad. Lincoln Borges Jr. Rio de Janeiro: Civilização Brasileira, 1968.

LOMBARDI, J. C. A Revolução soviética e a pedagogia histórico-crítica. In: ORSO, P. J.; MALANCHEN, J.; CASTANHA, A. P. (org.). Pedagogia histórico-crítica, educação e revolução: 100 anos da revolução russa. Campinas: Armazém do Ipê, 2017. p. 73-100. 
LUNACHARSKY, A. V. On literature and art. Trad. Ganushkin. Moscow: Progress Publishers, 1965.

LUNACHARSKY. A. V. Sobre la literatura y el arte. Trad. Ariel Bignami. Buenos Aires, Argentina: Axioma Editorial, 1974.

LUNATCHARSKY, A. V. As artes plásticas e a política na URSS. Trad. João Paulo Borges Coelho. Lisboa, Portugal: Editorial Estampa, 1975.

LUNATCHARKI, A. V. Artigos e discursos sobre a instrução e a educação. Trad. Filipe Guerra. Moscovo: Edições Progresso, 1988.

LUNATCHÁRSKI, A. V. Revolução, arte e cultura. São Paulo: Expressão Popular, 2018.

MAKARENKO, A. S. Conferências sobre educação infantil. Trad. Maria Aparecida A. Vizzoto. São Paulo: Moraes, 1981.

MANACORDA, M. A. História da educação: da antiguidade aos nossos dias. Trad. Gaetano Lo Monaco. 12. ed. São Paulo: Cortez, 2006.

MARIÁTEGUI, J. C. Revolução Russa: história, política e literatura. Trad. Luiz Bernardo Pericás. São Paulo: Expressão Popular, 2012.

MARX, K; ENGELS, F. A ideologia alemã. São Paulo: Hucitec, 1993.

MORAES, M. C. M. Recuo da teoria: dilemas na pesquisa em educação. Revista Portuguesa de Educação, Braga (Universidade do Minho), v. 14, n. 1, p. 7-25, 2001.

ORSO, P. J.; MALANCHEN, J.; CASTANHA, A. P. (org.). Pedagogia histórico-crítica, educação e revolução: 100 anos da revolução russa. Campinas: Armazém do Ipê, 2017.

PRESTES, Z. R. Quando não é quase a mesma coisa. Trad. Lev Semionovitch Vigotski no Brasil. Campinas, SP: Autores Associados, 2012.

REED, J. Os dez dias que abalaram o mundo: a história da Revolução Russa. Trad. Denise Tavares Gonçalves. Rio de Janeiro: Nova Fronteira, 2017. (Clássicos de Ouro)

SAVIANI, D.; DUARTE, N. A formação humana na perspectiva histórico-ontológica. Revista Brasileira de Educação, Rio de Janeiro, v. 15, n. 45, p. 422-590, set./dez. 2010.

TROTSKI. L. Literatura e Revolução. Trad. Luiz Alberto Moniz Bandeira. Rio de Janeiro: Zahar Editores, 2007.

VIGOTSKI, L. S. Imaginação e criação na infância. Trad. Zoia Prestes. São Paulo: Ática, 2009.

\section{Como referenciar este artigo}


CHAVES, M.; FELICIO, P. G.; MOREIRA, J. A. S. As contribuições de Anatoli Vassilievitch Lunatcharski para a educação brasileira na atualidade. Revista IberoAmericana de Estudos em Educação, Araraquara, v. 16, n. 3, p. 2133-2147, jul./set. 2021. e-ISSN: 1982-5587. DOI: https://doi.org/10.21723/riaee.v16i3.15414

Submetido em: $13 / 12 / 2020$

Revisões requeridas em: 07/01/2021

Aprovado em: 15/02/2021

Publicado em: 01/07/2021 